\title{
Role of Reaction and Factors of Carbon Nanotubes Growth in Chemical Vapour Decomposition Process Using Methane-A Highlight
}

\author{
Sivakumar VM, ${ }^{1}$ Abdul Rahman Mohamed, ${ }^{1}$ Ahmad Zuhairi Abdullah, ${ }^{1}$ \\ and Siang-Piao Chai ${ }^{2}$ \\ ${ }^{1}$ School of Chemical Engineering, Engineering Campus, Universiti Sains Malaysia, Seri Ampangan, Nibong Tebal, \\ Pulau Pinang 14300, Malaysia \\ ${ }^{2}$ School of Engineering, Monash University, Jalan Lagoon Selatan, Bandar Sunway, Selangor 46150, Malaysia
}

Correspondence should be addressed to Abdul Rahman Mohamed, chrahman@eng.usm.my

Received 5 November 2009; Accepted 13 April 2010

Academic Editor: Steve Acquah

Copyright (c) 2010 Sivakumar VM et al. This is an open access article distributed under the Creative Commons Attribution License, which permits unrestricted use, distribution, and reproduction in any medium, provided the original work is properly cited.

\begin{abstract}
One of the remarkable achievements in the field of nanotechnology is Carbon Nanotubes (CNT) synthesis. Since their discovery in 1991 by Iijima, CNTs have attracted much attention across the world. The CNTs are broadly classified into single-walled carbon nanotubes (SWNTs) and multiwalled carbon nanotubes (MWNTs). The most distinguished features of SWNTs and MWNTs are their electrical, mechanical, chemical, and electronic properties which in turn find their potential applications in almost all fields of science, engineering, and technology. Based on the previous research studies to till date, chemical vapour deposition (CVD) is considered to be the simplest method with high energy efficiency and precise control of reaction parameters compared to other different methods for synthesizing CNTs. Since production of CNTs is becoming the most important factor in the applications point of view, most industries today are opting for the CVD technique. This paper reviewed the synthesis of CNT by CVD especially focusing on methane CVD. Various parameters influencing the reaction and CNT growth were also discussed. A detailed review was made over the different types of CVD process, influence of metal, supports, metal-support interaction, effect of promoters, and reaction parameters role in CNTs growth.
\end{abstract}

\section{Introduction}

Carbon nanotubes (CNTs) are sheets of graphite rolled into tubes and possess excellent properties due to their symmetric structure [1]. They are broadly classified into single-walled carbon nanotubes (SWNTs) and multiwalled carbon nanotubes (MWNTs). Among them SWNTs are the key materials to the emerging field of nanotechnology [2]. CNTs have reached the forefront of many industrial research projects nowadays. Due to their high strength, stiffness, and electrical conductivity [3], CNTs are designated as one of the most attractive materials for reinforcing the material in composites $[4,5]$ and for nanoelectronics applications. Theoretical and experimental elastic modulus (1TPa) and tensile strength of these materials are in the range of tens of GPa, respectively [6]. In general, CNTs can be produced by carbon arc discharge method (CA) [7], chemical vapour deposition method (CVD) [8], pulsed laser vaporization technique (PLV) [9], and high-pressure carbon monoxide conversion (HiPco) process [10]. In CA and PLV methods, although high quality materials can be produced, the high temperature employed for evaporating the carbon atoms from solid carbon sources (over $3000 \mathrm{~K}$ ) make them difficult to scale up the process in a cost-effective way. Hence, chemical vapour decomposition (CVD) has gained importance owing to its easiest and economic way of production in a larger scale [11]. CVD method is believed as the most suitable synthesis method in terms of product quality and quantity [12]. A review by Baddour and Briens, 2005, concluded that catalytic technique such as CVD is simple, inexpensive, energy-efficient and can produce high purity CNTs in high yield $(>75 \%)$ [13]. As the applications for CNTs range from 
nanoelectronics $[14,15]$, sensors $[16,17]$, and field emitters [18] to composites [19], reliable growth techniques capable of yielding high-purity material in desirable quantities are critical to realize CNT potential. This need is satisfied by CVD and the CNT growth factors. Since, there is a huge demand for CNTs production and application in the global market, it is necessary to maximize the yield and minimize the production cost. Hence, methane, which is found to be the most cheaply available resource from natural gas with high thermal stability and low Gibbs free energy, is suitable to be used. In addition, the current focus on SWNTs synthesis and its requirement of low carbon content source are fulfilled by methane. These properties and advantages paved way for the recent research on CVD focused towards using methane as hydrocarbon source.

\section{Chemical Vapour Deposition}

Catalytic chemical vapour decomposition (CCVD) was first introduced by José-Yacamán et al. in 1993 to produce CNTs [20]. A simple representation of the chemical vapour deposition process is shown in Figure 1. CVD synthesis is achieved by putting carbon source in gas phase into a reactor and using an energy source, such as plasma or a resistively heated coil, to decompose the gaseous carbon molecule. In CCVD method, CNTs are produced by decomposition of carbon-containing molecules with the presence of catalytic materials. Commonly used carbon sources include methane, ethylene, hexane, ethanol, naphthalene, anthracene, carbon monoxide, carbon dioxide, acetylene, and benzene. Thermal or electrical energy source is used to crack the molecule into reactive atomic carbon. Then, the carbon diffuses into the supported metal, usually transition metal in Group VIII of the periodic table such as $\mathrm{Ni}, \mathrm{Fe}$, or Co. CNTs will be formed if the proper process conditions like reaction temperature, pressure, flow rate and concentration of hydrocarbon source, carrier gas, and so forth, are maintained. The appropriate metal catalyst among the transition group can grow SWNTs, DWNTs (double-walled carbon nanotubes), and MWNTs are shown in Figures 2(a), 2(b), and 2(c), respectively. Excellent alignment, size, diameter, growth rate as well as positional control on nanometer scale for the synthesized CNTs can be achieved by using CVD method.

2.1. Modified CVD Process. Nowadays the CVD process is under research with minor changes in their energy source to initiate the CNT growth. The process had been categorized according to their nature and source of energy (as shown in Figure 3). For examples, microwave [24, 25], inductively coupled plasma CVD [26], low pressure [27], hot filament (HF) [28, 29], alcohol catalytic [30], and so forth were reported.

Varadan and Xie [24], Fidalgo et al. [25] synthesized MWNTs by microwave CVD. The microwave system consists of a microwave magnetron with adjustable power supply ranging from 0 to $3000 \mathrm{~W}$ at a frequency of $2.45 \mathrm{GHz}$. No vacuum was maintained and reaction was operated at 1 atmosphere pressure. Straight and helical CNTs were

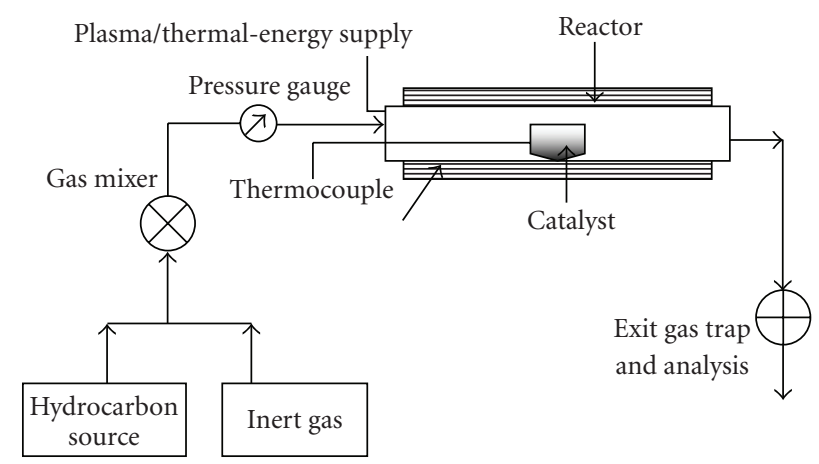

FIGURE 1: Schematic diagram of a CVD process for CNT synthesis.

obtained by decomposing acetylene in microwave energy field over the cobalt catalyst supported on Y-zeolite, alumina, and $\mathrm{SiC}$ at $700^{\circ} \mathrm{C}$. High resolution transmission electron microscope (HRTEM) analysis results confirmed the presence of MWNTs. It was also reported that CNTs obtained using alumina support was found to have more impurities than zeolite. The main advantage of microwave CVD system is rapid heating and cooling process with a chance to produce helical CNTs with diameter range 80-100 nm.

Ikuno et al. [27] produced CNTs by low-pressure thermal chemical deposition (LPTCD) using pure ethylene. CNT bridges were grown on Ta electrodes at $800^{\circ} \mathrm{C}$ in vacuum. By nitriding the surface of the Ta electrode $/ \mathrm{SiO}_{2} / \mathrm{Si}$ substrates, $\mathrm{Fe}$ nanoparticles with a moderate size were effectively formed, resulting in bridging CNTs between the electrodes. It was found that under a low pressure of $100 \mathrm{~Pa}$, straight CNTs are preferentially bridged between the Fe nanoparticles.

Yen et al. [26] synthesized well-aligned CNTs using a high inductively coupled plasma chemical vapor deposition (ICPCVD) system. A gas mixture of $\mathrm{CH}_{4}-\mathrm{H}_{2}$ was used as the carbon source and $\mathrm{Ni}$ as the catalyst for the CNTs growth. The effect of process parameters, such as inductive RF power, DC bias voltage and ratio, on the growth characteristics of CNTs was investigated. It was found that generation and transport of ions to the substrate are the two underlying factors in determining the growth of CNTs.

Kadlečíková et al. [28] studied the effect of electric field upon the aligned growth of CNTs and had successfully produced bundles of CNTs by hot filament CVD method. The author stated that the key role in the formation of CNTs depends on the energy of ion bombardment and plasma discharge applied during the growth of CNTs after temperature and pressure were set in the deposition chamber.

Although various types of plasma enhanced CVD with specialized power supplies such as microwave, hot filament [28], radio-frequency, and direct-current (DC) exist and recognized as the most promising technique in growing CNTs at a relatively low temperature, this technique has a drawback of difficulty in scaling up the plasma technology to grow CNTs on a large scale and high voltages used lead to the sputtering of the electrode, causing both contamination of the plasma and damage to the CNT structure. 


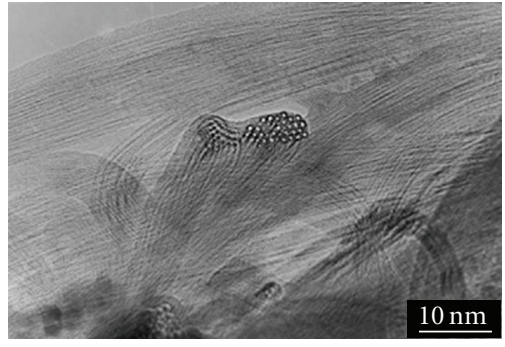

(a)

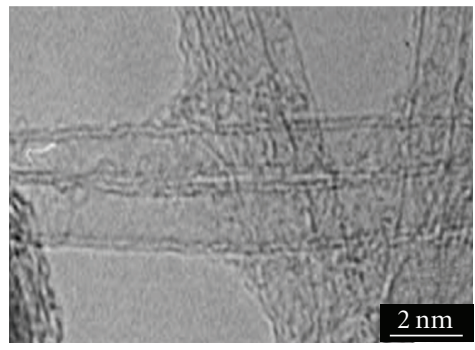

(b)

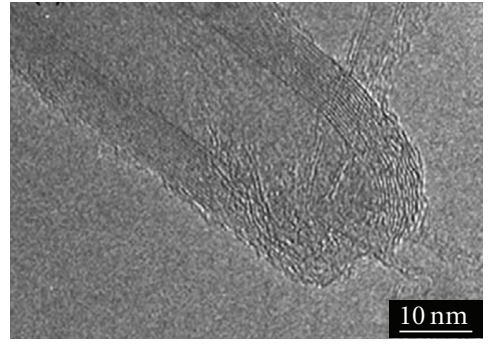

(c)

FiguRE 2: Transmission electron microscopy images (a) single-walled carbon nanotubes [21]; (b) double-walled carbon nanotubes [22]; (c) multiwalled carbon nanotubes [23].

Unalan and Chhowalla [30] investigated SWNT growth parameters using alcohol catalytic chemical vapour deposition (ACCVD). Alcohol vapours like ethanol or methanol were used as the carbon sources and a mixture of Fe-Co acetate was used as catalytic material with $\mathrm{MgO}$ as its support. Dip-coating method was utilized for loading catalyst particles on the substrate. SWNTs with narrow diameter distribution without the presence of amorphous carbon were obtained at temperatures above $750^{\circ} \mathrm{C}$, whereas defective MWNTs were observed at a lower temperature. It was reported that use of methanol as carbon source, with catalyst dissolved in deionised water (DI) rather than alcohol lead to growing more uniform SWNTs on the substrate surface.

In addition, a type of CCVD using fluidized bed reaction was also used for producing CNTs [30, 31]. Though the above techniques were tried with advancement in technologies, it still faces several drawbacks in scaling up the process. Moreover, the CCVD process is still found to be better for commercial synthesis of CNTs in proper controlled conditions $[32,33]$.

In the last decade, different techniques such as plasma enhanced CVD, thermal CVD, alcohol-catalytic (ACCVD) [34], vapour phase growth, and laser assisted CVD [35, 36] for the CNTs synthesis have been developed. Colomer et al. [37] confirmed that CCVD is easier, cheaper, and an adaptable approach for large-scale production CNTs at low temperature and ambient pressure via decomposing the hydrocarbon gas. Kong et al. [38] has already proved that CVD of methane can be a successful route for the growth of SWNTs.

2.2. Methane CVD. The following review has been made to highlight the current importance towards methane CVD in CNT synthesis using metal supported catalyst. Hightemperature decomposition of hydrocarbons leads to the formation of deposited carbon. Morphology of the carbon deposits over the catalyst/support during CVD process was closely related to the thermodynamic properties and nature of the hydrocarbon source. Gaseous hydrocarbons such as acetylene [39-41], methane [42, 43], and ethylene [27] have been widely used for producing CNT deposits. Besides gaseous hydrocarbons, some liquid hydrocarbons such as hexane, benzene [44], toluene [45], xylene [46], and so forth, have also been effectively used for the growth of SWNTs and MWNTs in floating CVD methods.

Li et al. [47] studied the effect of various hydrocarbons like methane, hexane, cyclohexane, benzene, naphthalene, and anthracene over Fe catalyst impregnated on $\mathrm{MgO}$ support. The author reported that there was a strong dependence of nature of hydrocarbon precursors on the formation of different structure of CNTs. It was also reported that methane would be most preferable for the growth of high-purity SWNTs rather than any other gaseous hydrocarbons, as it was comparatively chemically stable at high temperature and has the simplest structure [48]. However, the achievement for the methane CVD growth of SWNTs would largely depend on the features of catalyst as well.

de Almeida et al. [49] studied the methane decomposition using porous-nickel alumina spheres as catalyst. It was observed that during catalytic decomposition reaction, methane is initially absorbed and decomposed on the metal surface of the catalyst particle, resulting in the formation of chemisorbed carbon species and the release of gaseous hydrogen. The carbon species was found to proceed further to dissolve in and diffuse through the bulk of the metal particle. Some of the aromatic hydrocarbons like benzene could be decomposed at a lower temperature when compared with methane [50]. But it was experimentally proven that benzene decomposition temperature should be kept at $800^{\circ} \mathrm{C}$ to favor the SWNTs formation, whereas in the case of methane, it could be achieved at a lower temperature of $650^{\circ} \mathrm{C}$ with lower Gibbs free energy $(\Delta G=-27.2 \mathrm{KJ})$ [51]. SWNTs could not be obtained with hexane and cyclohexane though their reaction due to Gibbs free energies are much lower than that of benzene and methane. It was further revealed that the formation and morphology of carbon deposits were not simply determined by the pyrolytic behaviors of hydrocarbons.

Muradov [52] made a significant study of methane decomposition reaction (pressure: atmospheric, temperature: $850^{\circ} \mathrm{C}$, methane flow rate: $5.0 \pm 0.2 \mathrm{~mL} / \mathrm{min}$; sample amount: $0.3 \pm 0.001 \mathrm{~g}$ ) over 30 different samples of elemental carbon, including a variety of activated carbons (ACs), carbon blacks (CBs), nanostructured carbons (including CNTs and fullerenes), graphite, glassy carbon, and synthesized diamond powders. Catalytic activity of these carbons samples in methane decomposition was determined by their 


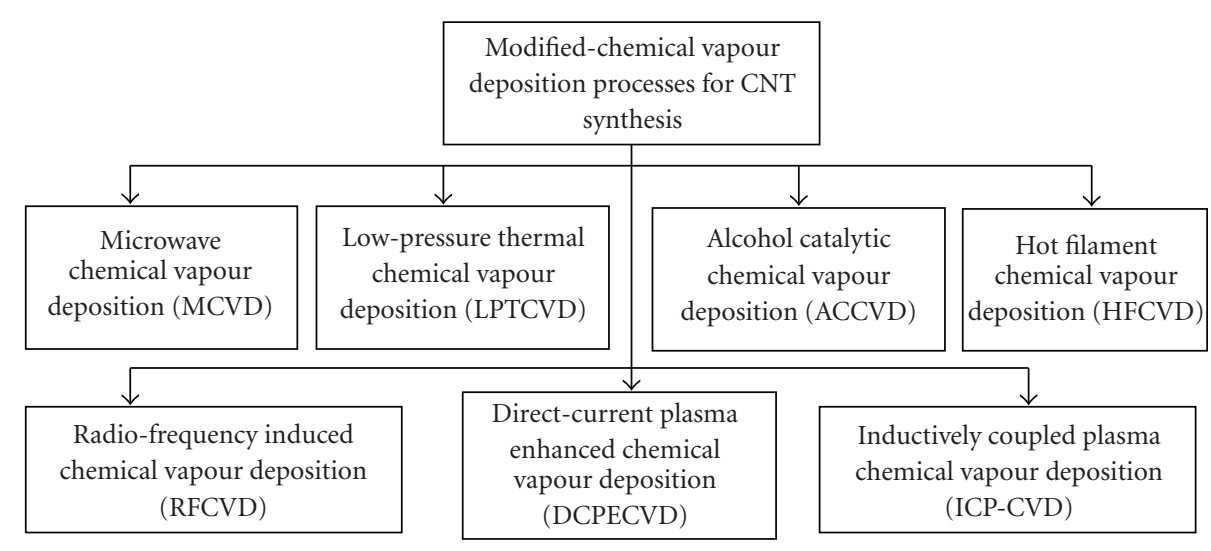

FIgURE 3: Classification of CVD processes according to their energy source.

origin, structure, and surface area. ACs were found to provide the highest initial activity of methane decomposition with $90 \mathrm{vol} \%$ of $\mathrm{H}_{2}$ formed for $10 \mathrm{~s}$ residence time with carbon sample bed. On the contrary, this highest methane decomposition rate with $\mathrm{CO} / \mathrm{CO}_{2}$-free hydrogen in a single step could not be obtained for experiments conducted with silica (surface area: $600 \mathrm{~m}^{2} / \mathrm{gm}$ ) and that of $\mathrm{Ni}$ - and Fe-based catalysts measured at identical conditions.

In 2007, Chuang et al. [53] developed sea urchin-like CNTs by catalytic decomposition of methane over catalystseeded mesoporous carbon and the catalysts were prepared by dip-coating method. The area density of CNTs/carbon nanowires (CNWs) was found to be higher at $900^{\circ} \mathrm{C}$ than that at $800^{\circ} \mathrm{C}$. Most recently, Chuang et al. [53] and Fidalgo et al. [25] investigated the growth of nanofilaments on activated carbon and carbon fibre materials by microwave-assisted methane decomposition and they found that for pure methane flow at $800^{\circ} \mathrm{C}$ for 130 minutes, only amorphous carbon was formed over the activated carbon and carbon fibres.

It can be concluded that the nature of hydrocarbons plays a crucial role in CVD process for CNT formation, as well in economic aspects. It should be noted that the formation of SWNTs or MWNTs does not merely depend on carbon precursors, but also has strong correlations with other growth conditions. Since methane being a rich source from natural gas, several studies of CCVD using methane as the hydrocarbon source are under progress for investigating the other growth influencing conditions like nature of metal catalysts, support, metal-support interaction, their characteristics, temperature, pressure, gas flow rate, concentration, reaction time, and so forth.

\section{CNT Growth Parameters}

Li et al. [23] studied that SWNTs or MWNTs formation does not alone depend on the nature of hydrocarbon source. There are also other important parameters playing more crucial role in the growth of different morphology of CNT. Based on distinguished CNT structure and chirality, their properties and end use applications are found to be significant. The main parameters for CNT growth are (i) properties, composition, and preparation method of metal catalyst, (ii) addition of promoter elements, (iii) metalsupport interactions, (iv) reaction conditions like reaction temperature, pressure, inert/methane gas ratio, and gas flow rate.

3.1. Catalyst. Metals used to catalyze CNT formation are most often transition metals, in particular iron (Fe), cobalt $(\mathrm{Co})$, and nickel $(\mathrm{Ni})$, due to the solubility of carbon in these metals is finite [54]. It is noteworthy to find a large number of literatures reporting about CNT growth using different metals and their alloys [55]. The main reason of using transition metals is that they have nonfilled "d" shells and for that reason it is able to interact with hydrocarbons and show catalytic activity. In CVD process, transition metal particles act as a seed of nanotubes so that they strongly influence the structure and quality of the nanotubes. Though the transition metals can decompose hydrocarbons, they need a support for the growth of nanotubes. Materials like silica $[56,57]$, alumina $[58,59]$, zeolite [44], and recently $\mathrm{MgO}$ [60-62] were used as supports for active metals in developing different forms of carbon nanostructures like SWNT, DWNT, MWNT, and nanofibres. Different catalyst preparation techniques like impregnation [63-69], coprecipitation [70], sol-gel technique [71-73], thin film deposition using electron beam evaporation, and photolithography [74] for patterned catalyst on the support were studied. Among the above mentioned techniques, wet impregnation is the easiest way and mostly adopted by many of the researchers for preparing the catalyst.

Ichi-oka et al. [68] made a comparative study for the amount of carbon deposited via CVD of methane using nine different metals ( $\mathrm{Fe}, \mathrm{Co}, \mathrm{Ni}, \mathrm{Ru}, \mathrm{Rh}, \mathrm{Pd}$, Os, Ir, and $\mathrm{Pt}$ ) catalyst impregnated over $\mathrm{MgO}$. It was reported that there was an increase in carbon content in the order of transition metal series: first $<$ second $<$ third row transition elements and the index of crystallinity $\left(\mathrm{I}_{\mathrm{G}} / \mathrm{I}_{\mathrm{D}}\right)$ for CNTs in Raman bands decreased in the order: $8>9>10$ group elements in the periodic table.

Qian et al. [75] reported that higher conversion of methane into good morphology of CNTs was achieved over 
Fe and Mo catalyst. It was also reported that the metal particles with relatively small diameter distribution, high activity and thermal stability at high temperatures would meet the requirements of thermodynamics of methane conversion. Combined process of catalyst reduction and hydrocarbon decomposition were found to result with higher yield of CNT. Qian et al. [75] studied Co catalyst impregnated over $\mathrm{Al}_{2} \mathrm{O}_{3}$ support and reported 3-4 times of higher yield for combined process rather than separated methane decomposition in fluidized bed reactor.

He et al. [76] studied on the morphology of vertically aligned CNTs by using Fe on silicon substrates by CVD process. It was reported that decrease in the thickness of catalyst film reduced the diameter and increased the length of CNTs. He et al. [42] studied methane CVD over $\mathrm{Ni} / \mathrm{Al}$ composite prepared by homogenous deposition and precipitation. The authors reported that MWNTs of 10$20 \mathrm{~nm}$ diameter range were formed from $20 \% \mathrm{wt} \mathrm{Ni}$ catalyst and carbon onions ( 5 to $50 \mathrm{~nm}$ ) from $80 \%$ wt Ni catalyst. It was further found that the $\mathrm{Ni} / \mathrm{Al}$ catalyst with $80 \mathrm{wt} \% \mathrm{Ni}$ is less beneficial for CNT growth due to its increasing particle size which in turn leads to very low carbon solubility and resulted with carbon onions growth.

Zhu et al. [21] found that methane CVD over $\mathrm{Co} / \mathrm{MgO}$ catalyst with the addition of Mo remarkably increased the yield of SWNTs by $10 \%$ at least with suppressed amorphous carbon formation. It was reported that too many metallic Co particles with respect to Mo and support would form aggregated larger particles during preparation resulting with MWNTs.

Proper control of the catalyst particle size and metal concentration is critical for a high production rate of CNT. Yu et al. [77] studied the effect of Fe catalyst on silica particle size by CO disproportion method and revealed that particle sizes of 13-15 nm are optimum for maximum CNT growth rate. Therefore, small particle sizes do not always lead to a high growth rate. Li et al. [47] studied methane CVD for Co catalyst impregnated over $\mathrm{MgO}$ support. Co concentrations of $2.5-5 \mathrm{wt} \%$ were found to be efficient for growing DWNTs with diameters of $2-4 \mathrm{~nm}$. It was reported that the growth was significantly influenced by catalyst concentration and type of supports. The important factors for a good catalyst are the control of the loading of the active metal and maintaining a good metal dispersion on the catalyst support [78].

Muradov [52] found that activated carbon (AC) catalyst played a significant role in methane conversion with initial $\mathrm{H}_{2}$ concentration reaching up to $90 \mathrm{vol} \%$. Also, it was stated that similar methane decomposition could not be achieved with silica gel (surface area: $600 \mathrm{~m}^{2} / \mathrm{gm}$ ) and that of Ni- \& Fe-based catalysts measured at the identical conditions. The mechanism of methane decomposition over different forms of carbon as catalyst and their activity were yet to be explored in CCVD process for CNTs growth.

3.2. Metal-Support Interaction. Catalyst supports are also reported to have great determination on the activity of a catalyst and the morphology of the produced CNTs. Metal-support interaction (MSI) is a very important factor in nanotube formation which is dependent on the nature of catalyst/support particle size, their surface area and the catalyst pretreatment process like calcination, reduction, and so forth. It has been found that CNT can be formed either with (i) tip-growth or (ii) base-growth model. Strong metal-support interaction of catalyst resulted CNTs to grow followed the base growth model, whereas tip-growth model is applied to CNTs grown by catalyst with weak MSI.

According to Vander Wal et al. [79] the formation of CNT structures is controlled by the effect of MSI. Though different sizes and shapes (helical, coiled, straight, and Y-shaped) of CNTs were produced so far, the growth mechanism of nanotubes is still a vague phenomenon for the researchers.

Several MSI studies for methane CVD have been carried out both in fluidized bed and fixed bed reactor system [80]. Catalytic performance of supported-NiO catalysts over methane decomposition at $550^{\circ} \mathrm{C}$ and $700^{\circ} \mathrm{C}$ by Chai et al. [81] shows that there is a decrease in activity of catalyst in the order of $\mathrm{NiO} / \mathrm{SiO}_{2}>\mathrm{NiO} / \mathrm{HZSM}-5>\mathrm{NiO} / \mathrm{CeO}_{2}>$ $\mathrm{NiO} / \mathrm{Al}_{2} \mathrm{O}_{3}$. From their XRD results, the dispersion of $\mathrm{NiO}$ particles on $\mathrm{Al}_{2} \mathrm{O}_{3}$ is found to be better compared to other support types. Also the formation of MWNTs at $550^{\circ} \mathrm{C}$ and SWNTs at $700^{\circ} \mathrm{C}$ is an indication of methane decomposition as well as the catalyst deactivation rate with respect to the increase in temperature. Similar studies on silica, zeolite, and alumina-supported Co catalysts for MWNT by acetylene decomposition show that percentage carbon deposition and diameter of CNT formed are based on the type and nature of support material [82]. The size of the pores on porous substrates determines the SWNTs or MWNTs formation. Substrate roughness studies by Ward et al. [11] also emphasize on the future research on substrate-catalyst interaction mechanism towards CNTs growth.

de Almeida et al. [49] quoted that methane decomposition at low temperatures $\left(400-500^{\circ} \mathrm{C}\right)$ can be achieved using binary metal ( $\mathrm{Fe}-\mathrm{M}$ where $\mathrm{M}=\mathrm{Pd}, \mathrm{Mo}$, or $\mathrm{Ni}$ ) catalysts supported on alumina. Also, Muradov [52] studied methane decomposition over elemental carbon and reported that carbon materials are capable of producing $\mathrm{H}_{2}$ rich gases at moderate temperatures. The author stated that catalytic activity of carbon was determined by their origin and surface properties. At higher temperature, such as at $830^{\circ} \mathrm{C}, \mathrm{NiAl}_{2} \mathrm{O}_{4}$ phase is formed due to the strong metal-support interaction. Methane decomposition conversion values were found to increase with increasing reaction temperature. Hence, it can be concluded that the lower calcination temperature gave the catalyst with weak MSI but increased the methane conversion. In the case of higher calcination temperatures, $\mathrm{Ni}$ was incorporated strongly with alumina and thus methane conversion was low.

Ward et al. [11] studied CNT synthesis on various substrates (alumina, silica carbide, silicon, quartz, sapphire, $\mathrm{MgO}$, porous silicon, aerogel, fused silica, etc.) and its effect with Al-Fe-Mo by multilayer thin films deposition (electron beam evaporation). They found that Fe thin films spun on alumina to be the best for growing SWNTs and all other supports would give the formation of MWNTs primarily. 


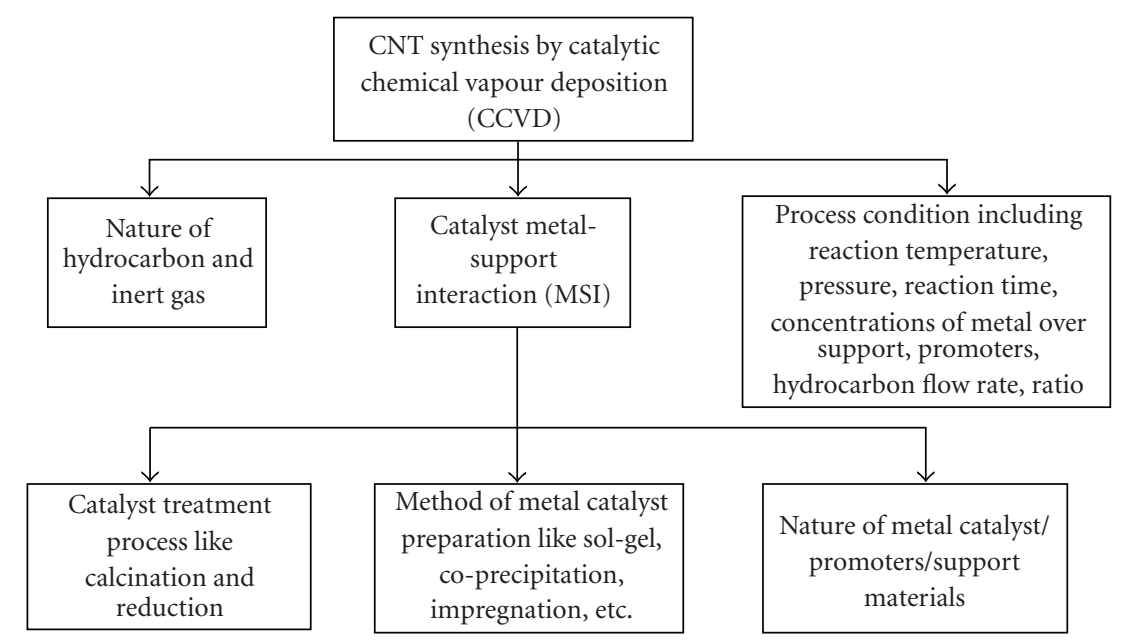

FIGURE 4: The network of the important factors for CNT synthesis.

Authors reported that the property of the substrates/supports like amount of crystallinity, pore size, and surface roughness had a major effect in the growth of either SWNTs or MWNTs

Chai et al. [83] studied the effect of $\mathrm{CuO}, \mathrm{FeO}$, and $\mathrm{NiO}$ added onto $\mathrm{CoO} / \mathrm{Al}_{2} \mathrm{O}_{3}$ for methane decomposition. It was found that addition of these metal oxides shortened the catalyst lifetime and decreased the methane conversion. Catalyst lifetime and carbon capacity were found to increase with $\mathrm{MoO}-\mathrm{CoO} / \mathrm{Al}_{2} \mathrm{O}_{3}$. The carbon capacity over the supported $\mathrm{CoO}$ catalyst was found to decrease in the order of silica $>$ zeolite $>$ alumina $>$ ceria $>$ titania $>$ magnesia $>$ calcium oxide and the best catalytic carbon capacity was observed over $\mathrm{CoO} / \mathrm{SiO}_{2}$.

According to various researches, it was found that catalyst with weak MSI is efficient in methane decomposition whereas, for a catalyst with strong MSI, the metal particles are not easily detached from the support. Moreover, strong interaction increased the surface carbon accumulation over catalyst and enhanced the catalyst deactivation in methane decomposition.

3.3. Promoters. Some of the metals like molybdenum, boron [84], and sulphur [85] have been used as promoters for catalyst towards the decomposition of hydrocarbon gas into Y-shaped and helical CNTs. Molybdenum was found to be an effective dispersive agent for the catalyst when it is present at the optimum composition in the catalysts as reported by Yu et al. [62]. Ago et al. [86] found that the catalytic activity increases in the following order Fe-Mo $>\mathrm{Fe}>\mathrm{Co}>\mathrm{Ni}$. The addition of molybdenum to iron catalyst increases the initial methane conversion and prevents the rapid deactivation of the catalyst.

Li et al. [47] studied the effect of Mo on MgO support. The formation of magnesium molybdate $\left(\mathrm{MgMoO}_{4}\right)$ phase was found to play a main role in MWNT synthesis. They suggested that ratio of $\mathrm{Mo} / \mathrm{Mg}$ should be $<1$ for the growth of MWNT bundles. It was found that an appropriate amount of water vapour on the catalytic nanotube growth increases the CNT yield by 35\%. Zhu et al. [21] showed that addition of molybdenum $(\mathrm{Mo} / \mathrm{Co}=1 / 5)$ in an optimum level to $\mathrm{Co} / \mathrm{MgO}$ catalysts (prepared by mechanical mixing and combustion synthesis with citric acid) yielded 10 time's higher generation of SWNTs and less amorphous carbon. Liu et al. [48] studied the CCVD of methane over $\mathrm{Fe}-\mathrm{Mo} / \mathrm{Al}_{2} \mathrm{O}_{3}$ catalyst. They reported that the yield of $70 \%$ SWNTs and $30 \%$ DWNTs are related to the weight of Fe-Mo metal in $\mathrm{Fe}-\mathrm{Mo} / \mathrm{Al}_{2} \mathrm{O}_{3}$. Similarly, Kang et al. [87] synthesized SWNTs and DWNTs over $\mathrm{Fe}-\mathrm{Mo} / \mathrm{MgO}$ catalyst and reported that proportion of DWNTs increased with an increase in reaction temperature. Moreover, Mo was known to be a catalytic centre for promoting the aromatization of methane. Zhang et al. [78] synthesized DWNTs by methane CVD on Fe/Al/MgO catalyst. The author found that introduction of $\mathrm{Al}$ species into $\mathrm{Fe} / \mathrm{MgO}$ would reduce the size of $\mathrm{MgO}$ crystallites, providing a better dispersion of the metal particles on the support.

Sulfur was introduced as an additive in methane CVD process for the production of CNTs over $\mathrm{Co}-\mathrm{Mo} / \mathrm{MgO}$ catalyst prepared with sol-gel method [85]. It was found that the use of sulfur compounds during the sol-gel catalyst preparation process led to a significant change in the matrix composition and matrix-catalyst interaction. In this case, enhanced growth of Helical (HCNTs) was reported. Similarly, Y-shaped CNTs (YCNTs) growth was favored when sulfur in the form of thiophene vapours was used over the sol-gel prepared Co-Mo/MgO catalyst.

Phosphorous was reported in the literature by $\mathrm{Ci}$ et al. [88] for promoting effect in the formation of carbon filaments. Addition of phosphorous from a solution of $\mathrm{H}_{3} \mathrm{PO}_{4}$ in ethanol to the substrate, and followed by impregnation with $\mathrm{Fe}_{3}(\mathrm{CO})_{12}$ was found to be effective in promoting the growth of vapour grown carbon fibres (VGCFs) [89]. Also, it was found that an increase in the amount of Phosphorous/Fe ratio $>0.25$ had an inhibiting effect on the VGCFs. He et al. [59] synthesized binary and triple CNTs over $\mathrm{Ni} / \mathrm{Cu} / \mathrm{Al}_{2} \mathrm{O}_{3}$ in the ratio $2: 1: 1$ (prepared by sol-gel method) using -20 mesh to +40 mesh particles size for methane CVD at $550^{\circ} \mathrm{C}$ and the findings show that copper element provoked the formation of CNT. 


\section{Reaction Parameters}

The impact of reaction parameters like reaction temperature, reaction time, concentration of $\mathrm{H}_{2}$, and flow rate ratio $\left(\mathrm{CH}_{4}: \mathrm{H}_{2}\right)$ plays a major role in deciding the types of CNTs formation, and its yield. Recently, studies on effect of aforementioned reaction parameters in CNT formation using methane CVD in presence of $\mathrm{Ni}-\mathrm{Mo} / \mathrm{MgO}$ were reported by Zhan et al. [90]. Morphological structure of CNTs was also found to depend much on the reaction temperatures [91], reaction time [92], and $\mathrm{CH}_{4}$ to $\mathrm{H}_{2}$ gas ratio [93] in methane CVD.

Yu et al. [62] studied the influence of reaction atmosphere on $\mathrm{Fe} / \mathrm{MgO}$ and $\mathrm{Fe}-\mathrm{Mo} / \mathrm{MgO}$ catalyst in argon and nitrogen by methane CVD. It was reported that there was an increase in diameter of SWNTs, MWNTs, and CNFs formed as the reaction was enriched in nitrogen atmosphere. On the other hand, pure SWNTs were obtained with Ar atmosphere. $\mathrm{Ni}$ et al. [61] studied the kinetics of CNT synthesis by methane $\mathrm{CVD}$ over $\mathrm{Mo} / \mathrm{Co} / \mathrm{MgO}$ and $\mathrm{Co} / \mathrm{MgO}$ catalyst. It was found, the rate of CNT synthesis is proportional to the methane pressure, indicating that the dissociation of methane is the rate-determining step for a catalyst.

Zhao et al. $[94,95]$ claimed that reaction time would influence the morphology and diameter of CNTs. Carbon onions and two kinds of herringbone CNFs were obtained with $5 \mathrm{wt} \% \mathrm{Ni}$ coprecipitated aluminium matrix. The catalysts used were calcined at $240^{\circ} \mathrm{C}$ and $400^{\circ} \mathrm{C}$ for 2 hours. Decomposition reaction was conducted in horizontal quartz boat at $550^{\circ} \mathrm{C} / 600^{\circ} \mathrm{C}$ for 1 hour and 2 hours by varying the ratio of $\mathrm{CH}_{4}: \mathrm{N}_{2}$ from $1: 4$ to $1: 5.5$. The findings confirmed that carrier gas $\left(\mathrm{N}_{2}\right)$ plays an important role in CNT synthesis. The authors reported that cone-shaped catalyst was formed at $550^{\circ} \mathrm{C}$ and cylinder shape catalyst at $600^{\circ} \mathrm{C}$. Influence of temperature over the shape and size of the catalyst was reported and thus the morphology of herringbone CNFs. Hence, by extending the growth time from 1 to 2 hours, carbon onions were formed.

Noda et al. [96] quoted various studies on methane decomposition over different catalyst and supports for the formation of SWNTs and MWNTs at different reaction temperatures. Effect of $1 \%$ and $5 \%$ of $\mathrm{Ni}$ loaded on $\mathrm{SiO}_{2}$ in the temperature range of $625-800^{\circ} \mathrm{C}$ were studied in a fixed bed quartz tube reactor. Catalyst with $1 \% \mathrm{Ni}$ favored SWNT formation at all reaction temperatures whereas $5 \%$ $\mathrm{Ni}$ formed MWNTs at low temperature and SWNT at high temperature. Also, it was found that the amount of CNT decreased at high temperature for both concentrations due to sintering process.

de Almeida et al. [49] studied $\mathrm{CH}_{4}$ deposition by preheating $\mathrm{Ni} / \mathrm{Al}_{2} \mathrm{O}_{3}$ samples at 350,550 and $700^{\circ} \mathrm{C}$ under air flow for 1 hour and reaction at atmospheric pressure with molar ratio of $\mathrm{N}_{2}: \mathrm{CH}_{4}=6: 1$ at $600^{\circ} \mathrm{C}, 700^{\circ} \mathrm{C}$, and $800^{\circ} \mathrm{C}$. He reported that higher calcination temperature lowers the residual amorphous carbon present within the pores of crystalline catalyst sample, resulting in mesopore formation and increasing surface area and pore volume.

Qian et al. [31] investigated the combination of catalyst reduction and methane decomposition over $\mathrm{Ni}$ and $\mathrm{Co}$ in fluidized bed reactor. $\mathrm{Co} / \mathrm{Mo} / \mathrm{Al}_{2} \mathrm{O}_{3}$ of ratio $1 / 4 / 50 \mathrm{wt}$ ratio and $\mathrm{Ni} / \mathrm{Cu} / \mathrm{Al}_{2} \mathrm{O}_{3}$ of $15 / 3 / 2 \mathrm{wt}$ were prepared by coprecipitation and decomposed in the range of $550^{\circ} \mathrm{C}-$ $850^{\circ} \mathrm{C}$ with methane to argon ratio of $1: 1$. Higher methane conversion and 3-4 times better yield of CNTs were reported for this combination. He states that when the metal catalysts are reduced, they provide energy for the endothermic methane decomposition and make methane decomposition equilibrium shift to the direction of hydrogen \& carbon and CNTs production.

Bustero et al. [97] studied the effect of temperature, mass of catalyst, initial feed gas composition, and reaction time on the yield of CNT. Optimal operating conditions for the synthesis of CNTs by CVD as reported by the authors are the reaction time: $10 \mathrm{~min}$; temperature: $1000^{\circ} \mathrm{C}$; catalyst Mass: $0.5 \mathrm{~g}$; ratio of $\mathrm{H}_{2} / \mathrm{CH}_{4}$ is $1: 1$. A mathematical expression was established between the processing condition and the yield of carbon deposits. The derived expression also confirms that it is difficult to determine the optimal reaction conditions for the CNT synthesis by CVD.

$\mathrm{Ni}$ et al. [61] studied the effect of pressure and temperature on $\mathrm{CNT}$ synthesis by methane $\mathrm{CVD}$ over $\mathrm{Mo} / \mathrm{Co} / \mathrm{MgO}$ and $\mathrm{Co} / \mathrm{MgO}$ catalyst. An increase in carbon yield was observed for an increase in methane pressure from 7.5 Torr to 78.0 Torr. Even at high methane pressures, no significant deactivation of the $\mathrm{Mo} / \mathrm{Co} / \mathrm{MgO}$ catalysts was noted. It was found that the rate of methane disassociation was reduced due to the addition of Mo into $\mathrm{Co} / \mathrm{MgO}$ catalysts.

In 2007, Chuang et al. [53] conducted catalytic methane CVD over metal catalyst supported over mesoporous carbon (prepared by dip-coating method) at different temperatures $\left(800^{\circ} \mathrm{C}\right.$ and $\left.900^{\circ} \mathrm{C}\right)$. It was concluded that at $900^{\circ} \mathrm{C}$, CNTs and carbon nanowires (CNWs) could be obtained in high density rather than at $800^{\circ} \mathrm{C}$. Recently, Fidalgo et al. [25] studied the influence of different $\mathrm{CH}_{4} / \mathrm{N}_{2}$ ratio with respect to nanofilaments formation. Methane CVD was conducted over $\mathrm{Fe}$ and $\mathrm{Ni}$ catalyst impregnated over activated carbon and carbon fibres at $800^{\circ} \mathrm{C}$ for 130 minutes. The growth of nanofilaments was found to be more abundant using $\mathrm{CH}_{4}: \mathrm{N}_{2}$ ratio of $1: 3$ rather than $1: 1$. It is concluded that the presence of $\mathrm{N}_{2}$ in methane CVD could influence the carbon yield. The factors of CNT growth have been summarized in the Figure 4.

It was found that methane CVD processes had been influenced by the process and CNT growth parameters like methane/carrier gas ratio, reduction atmosphere, methane/inert gas volumetric flow rate, reaction temperature, time of reaction and operating pressure, and so forth, Hence all the above-mentioned parameters would be crucial in deciding the nature, properties, yield, and quality of CNTs.

\section{Conclusions}

The current focus on the CCVD of methane for CNTs synthesis was reviewed. Methane being a highly available hydrocarbon source with high thermal stability and thermodynamic properties as discussed, still needs to be studied with the other influencing parameters on CNT growth. 
The carbon-based supports like AC is found to be a good material in decomposing methane at low temperatures. As mentioned by various researchers, each step starting from the metal catalyst preparation to removal of impurities from the synthesized CNTs would reflect in its product type, quality, yield, and ultimately its market demand for their potential applications. In the economic aspects, the value of CNT material, which at present greater than the value of gold, can be made available in bulk by proper control and optimization of the reaction parameters. Growth mechanism, which is still a vague phenomenon for many researchers, needs further investigations. Method of purification, a deciding factor for the purity of CNTs, needs to be identified to selectively separate the material based on its shape and size. At present, several research studies on CVD reaction using fixed/fluidized bed with horizontal/vertical reactors and CNTs growth parameters are being conducted only in lab scale. Hence, it is of the opinion to further explore the potential of using methane as hydrocarbon source with carbon-based supports for metal catalyst will be an opt route to the bulk and low-cost production of CNTs to meet the future global demand.

\section{Acknowledgments}

The authors gratefully acknowledge the financial support provided by the Ministry of Science, Technology and Innovations (MOSTI) under E-Science Fund (Project A/c no: 6013327) and the Universiti Sains Malaysia (USM) for funding this project under the Research University (RU) Grant Scheme (Project A/c No: 814004) and Student Fellowship.

\section{References}

[1] E. B. Barros, A. Jorio, G. G. Samsonidze, et al., "Review on the symmetry-related properties of carbon nanotubes," Physics Reports, vol. 431, no. 6, pp. 261-302, 2006.

[2] S. B. Sinnott and R. Andrews, "Carbon nanotubes: synthesis, properties, and applications," Critical Reviews in Solid State and Materials Sciences, vol. 26, no. 3, pp. 145-249, 2001.

[3] Z. L. Wang, P. Poncharal, and W. A. de Heer, "Measuring physical and mechanical properties of individual carbon nanotubes by in situ TEM," Journal of Physics and Chemistry of Solids, vol. 61, no. 7, pp. 1025-1030, 2000.

[4] P. M. Ajayan, L. S. Schadler, C. Giannaris, and A. Rubio, "Single-walled carbon nanotube-polymer composites: strength and weakness," Advanced Materials, vol. 12, no. 10, pp. 750-753, 2000.

[5] K. T. Lau, M. Lu, and D. Hui, "Coiled carbon nanotubes: synthesis and their potential applications in advanced composite structures," Composites Part B, vol. 37, no. 6, pp. 437-448, 2006.

[6] Z. L. Wang, R. P. Gao, P. Poncharal, W. A. de Heer, Z. R. Dai, and Z. W. Pan, "Mechanical and electrostatic properties of carbon nanotubes and nanowires," Materials Science and Engineering C, vol. 16, no. 1-2, pp. 3-10, 2001.

[7] S. Iijima, "Helical microtubules of graphitic carbon," Nature, vol. 354, no. 6348, pp. 56-58, 1991.
[8] M. Endo, K. Takeuchi, S. Igarashi, K. Kobori, M. Shiraishi, and H. W. Kroto, "The production and structure of pyrolytic carbon nanotubes (PCNTs)," Journal of Physics and Chemistry of Solids, vol. 54, no. 12, pp. 1841-1848, 1993.

[9] T. Guo, P. Nikolaev, A. Thess, D. T. Colbert, and R. E. Smalley, "Catalytic growth of single-walled manotubes by laser vaporization," Chemical Physics Letters, vol. 243, no. 1-2, pp. 49-54, 1995.

[10] P. Nikolaev, M. J. Bronikowski, R. K. Bradley, et al., "Gasphase catalytic growth of single-walled carbon nanotubes from carbon monoxide," Chemical Physics Letters, vol. 313, no. 1-2, pp. 91-97, 1999.

[11] J. W. Ward, B. Q. Wei, and P. M. Ajayan, "Substrate effects on the growth of carbon nanotubes by thermal decomposition of methane," Chemical Physics Letters, vol. 376, no. 5-6, pp. 717725, 2003.

[12] B. Zheng, Y. Li, and J. Liu, "CVD synthesis and purification of single-walled carbon nanotubes on aerogel-supported catalyst," Applied Physics A, vol. 74, no. 3, pp. 345-348, 2002.

[13] C. E. Baddour and C. Briens, "Carbon nanotube synthesis: a review," International Journal of Chemical Reactor Engineering, vol. 3, 2005.

[14] P. Avouris, T. Hertel, R. Martel, T. Schmidt, H. R. Shea, and R. E. Walkup, "Carbon nanotubes: nanomechanics, manipulation, and electronic devices," Applied Surface Science, vol. 141, no. 3-4, pp. 201-209, 1999.

[15] K. Tsukagoshi, N. Yoneya, S. Uryu, et al., "Carbon nanotube devices for nanoelectronics," Physica B, vol. 323, no. 1-4, pp. 107-114, 2002.

[16] G. A. Rivas, M. D. Rubianes, M. C. Rodríguez, et al., "Carbon nanotubes for electrochemical biosensing," Talanta, vol. 74, no. 3, pp. 291-307, 2007.

[17] Y. Yun, Z. Dong, V. Shanov, et al., "Nanotube electrodes and biosensors," Nano Today, vol. 2, no. 6, pp. 30-37, 2007.

[18] R. Martel, T. Schmidt, H. R. Shea, T. Hertel, and P. Avouris, "Single- and multi-wall carbon nanotube field-effect transistors," Applied Physics Letters, vol. 73, no. 17, pp. 2447-2449, 1998.

[19] J. N. Coleman, U. Khan, W. J. Blau, and Y. K. Gun'ko, “Small but strong: a review of the mechanical properties of carbon nanotube-polymer composites," Carbon, vol. 44, no. 9, pp. 1624-1652, 2006.

[20] M. José-Yacamán, M. Miki-Yoshida, L. Rendón, and J. G. Santiesteban, "Catalytic growth of carbon microtubules with fullerene structure," Applied Physics Letters, vol. 62, no. 2, pp. 202-204, 1993.

[21] H. Zhu, X. Li, C. Xu, and D. Wu, "Co-synthesis of single-walled carbon nanotubes and carbon fibers," Materials Research Bulletin, vol. 37, no. 1, pp. 177-183, 2002.

[22] W. Ren, F. Li, J. Chen, S. Bai, and H.-M. Cheng, "Morphology, diameter distribution and Raman scattering measurements of double-walled carbon nanotubes synthesized by catalytic decomposition of methane," Chemical Physics Letters, vol. 359, no. 3-4, pp. 196-202, 2002.

[23] Q. Li, H. Yan, J. Zhang, and Z. Liu, "Effect of hydrocarbons precursors on the formation of carbon nanotubes in chemical vapor deposition," Carbon, vol. 42, no. 4, pp. 829-835, 2004.

[24] V. K. Varadan and J. Xie, "Large-scale synthesis of multi-walled carbon nanotubes by microwave CVD," Smart Materials and Structures, vol. 11, no. 4, pp. 610-616, 2002.

[25] B. Fidalgo, Y. Fernández, L. Zubizarreta, et al., "Growth of nanofilaments on carbon-based materials from microwaveassisted decomposition of CH4," Applied Surface Science, vol. 254, no. 11, pp. 3553-3557, 2008. 
[26] J. H. Yen, I. C. Leu, C. C. Lin, and M. H. Hon, "Synthesis of well-aligned carbon nanotubes by inductively coupled plasma chemical vapor deposition," Applied Physics A, vol. 80, no. 2, pp. 415-421, 2005.

[27] T. Ikuno, M. Katayama, N. Yamauchi, et al., "Selective growth of straight carbon nanotubes by low-pressure thermal chemical vapor deposition," Japanese Journal of Applied Physics, vol. 43, no. 2, pp. 860-863, 2004.

[28] M. Kadlečíková, A. Vojačková, J. Breza, V. Luptáková, M. Michalka, and K. Jesenák, "Bundles of carbon nanotubes grown on sapphire and quartz substrates by catalytic hot filament chemical vapor deposition," Materials Letters, vol. 61, no. 23-24, pp. 4549-4552, 2007.

[29] H. Y. Yap, B. Ramaker, A. V. Sumant, and R. W. Carpick, "Growth of mechanically fixed and isolated vertically aligned carbon nanotubes and nanofibers by DC plasma-enhanced hot filament chemical vapor deposition," Diamond \& Related Materials, vol. 15, no. 10, pp. 1622-1628, 2006.

[30] H. E. Unalan and M. Chhowalla, "Investigation of singlewalled carbon nanotube growth parameters using alcohol catalytic chemical vapour deposition," Nanotechnology, vol. 16, no. 10, pp. 2153-2163, 2005.

[31] W. Qian, T. Liu, F. Wei, Z. Wang, and Y. Li, "Enhanced production of carbon nanotubes: combination of catalyst reduction and methane decomposition," Applied Catalysis A, vol. 258, no. 1, pp. 121-124, 2004.

[32] T. V. Reshetenko, L. B. Avdeeva, Z. R. Ismagilov, and A. L. Chuvilin, "Catalytic filamentous carbon as supports for nickel catalysts," Carbon, vol. 42, no. 1, pp. 143-148, 2004.

[33] R. Bonadiman, M. D. Lima, M. J. de Andrade, and C. P. Bergmann, "Production of single and multi-walled carbon nanotubes using natural gas as a precursor compound," Journal of Materials Science, vol. 41, no. 22, pp. 7288-7295, 2006.

[34] K. Y. Tran, B. Heinrichs, J.-F. Colomer, J.-P. Pirard, and S. Lambert, "Carbon nanotubes synthesis by the ethylene chemical catalytic vapour deposition (CCVD) process on Fe, $\mathrm{Co}$, and $\mathrm{Fe}-\mathrm{Co} / \mathrm{Al}_{2} \mathrm{O}_{3}$ sol-gel catalysts," Applied Catalysis A, vol. 318, pp. 63-69, 2007.

[35] N. Inami, M. Ambri Mohamed, E. Shikoh, and A. Fujiwara, "Synthesis-condition dependence of carbon nanotube growth by alcohol catalytic chemical vapor deposition method," Science and Technology of Advanced Materials, vol. 8, no. 4, pp. 292-295, 2007.

[36] R. Longtin, C. Fauteux, R. Goduguchinta, and J. Pegna, "Synthesis of carbon nanofiber films and nanofiber composite coatings by laser-assisted catalytic chemical vapor deposition," Thin Solid Films, vol. 515, no. 5, pp. 2958-2964, 2007.

[37] J.-F. Colomer, J.-M. Benoit, C. Stephan, S. Lefrant, G. Van Tendeloo, and J. B.nagy, "Characterization of single-wall carbon nanotubes produced by CCVD method," Chemical Physics Letters, vol. 345, no. 1-2, pp. 11-17, 2001.

[38] J. Kong, A. M. Cassell, and H. Dai, "Chemical vapor deposition of methane for single-walled carbon nanotubes," Chemical Physics Letters, vol. 292, no. 4-6, pp. 567-574, 1998.

[39] K. Hernadi, Z. Kónya, A. Siska, et al., "The role of zeotype catalyst support in the synthesis of carbon nanotubes by CCVD," Studies in Surface Science and Catalysis, vol. 142, pp. 541-548, 2002.

[40] T. Hiraoka, T. Kawakubo, J. Kimura, et al., "Selective synthesis of double-wall carbon nanotubes by CCVD of acetylene using zeolite supports," Chemical Physics Letters, vol. 382, no. 5-6, pp. 679-685, 2003.
[41] B. C. Liu, S. C. Lyu, S. I. Jung, et al., "Single-walled carbon nanotubes produced by catalytic chemical vapor deposition of acetylene over Fe-Mo/MgO catalyst," Chemical Physics Letters, vol. 383, no. 1-2, pp. 104-108, 2004.

[42] C. He, N. Zhao, C. Shi, X. Du, and J. Li, "Carbon nanotubes and onions from methane decomposition using Ni/Al catalysts," Materials Chemistry and Physics, vol. 97, no. 1, pp. 109$115,2006$.

[43] N. Zhao, Q. Cui, C. He, et al., "Synthesis of carbon nanostructures with different morphologies by CVD of methane," Materials Science and Engineering A, vol. 460-461, pp. 255260, 2007.

[44] Y. Yang, Z. Hu, Y. N. Lü, and Y. Chen, "Growth of carbon nanotubes with metal-loading mesoporous molecular sieves catalysts," Materials Chemistry and Physics, vol. 82, no. 2, pp. 440-443, 2003.

[45] K. Kidena, Y. Kamiyama, and M. Nomura, "A possibility of the production of carbon nanotubes from heavy hydrocarbons," Fuel Processing Technology, vol. 89, no. 4, pp. 449-454, 2008.

[46] H. Liu, G. Cheng, R. Zheng, Y. Zhao, and C. Liang, "Influence of synthesis process on preparation and properties of Ni/CNT catalyst," Diamond \& Related Materials, vol. 15, no. 1, pp. 1521, 2006.

[47] Y. Li, X. Zhang, X. Tao, et al., "Growth mechanism of multiwalled carbon nanotubes with or without bundles by catalytic deposition of methane on $\mathrm{Mo} / \mathrm{MgO}$," Chemical Physics Letters, vol. 386, no. 1-3, pp. 105-110, 2004.

[48] B. C. Liu, S. C. Lyu, T. J. Lee, et al., "Synthesis of single- and double-walled carbon nanotubes by catalytic decomposition of methane," Chemical Physics Letters, vol. 373, no. 5-6, pp. 475-479, 2003.

[49] R. M. de Almeida, H. V. Fajardo, D. Z. Mezalira, et al., "Preparation and evaluation of porous nickel-alumina spheres as catalyst in the production of hydrogen from decomposition of methane," Journal of Molecular Catalysis A, vol. 259, no. 1-2, pp. 328-335, 2006.

[50] R. C. Haddon, J. Sippel, A. G. Rinzler, and F. Papadimitrakopoulos, "Purification and separation of carbon nanotubes," MRS Bulletin, vol. 29, no. 4, pp. 252-241, 2004.

[51] Y. Ando, X. Zhao, T. Sugai, and M. Kumar, "Growing carbon nanotubes," Materials Today, vol. 7, no. 9, pp. 22-29, 2004.

[52] N. Muradov, "Catalysis of methane decomposition over elemental carbon," Catalysis Communications, vol. 2, no. 3-4, pp. 89-94, 2001.

[53] C.-M. Chuang, S. P. Sharma, J.-M. Ting, H.-P. Lin, H. Teng, and C.-W. Huang, "Preparation of sea urchin-like carbons by growing one-dimensional nanocarbon on mesoporous carbons," Diamond \& Related Materials, vol. 17, no. 4-5, pp. 606-610, 2008.

[54] A.-C. Dupuis, "The catalyst in the CCVD of carbon nanotubes-a review," Progress in Materials Science, vol. 50, no. 8, pp. 929-961, 2005.

[55] I. Vesselényi, K. Niesz, A. Siska, et al., "Production of carbon nanotubes on different metal supported catalysts," Reaction Kinetics and Catalysis Letters, vol. 74, no. 2, pp. 329-336, 2001.

[56] K. Hernadi, A. Fonseca, J. B. Nagy, D. Bernaerts, A. Fudala, and A. A. Lucas, "Catalytic synthesis of carbon nanotubes using zeolite support," Zeolites, vol. 17, no. 5-6, pp. 416-423, 1996.

[57] R. Wang, H. Xu, L. Guo, and J. Liang, "Growth of single-walled carbon nanotubes on porous silicon," Applied Surface Science, vol. 252, no. 20, pp. 7347-7351, 2006.

[58] W. Wongwiriyapan, M. Katayama, T. Ikuno, et al., "Growth of single-walled carbon nanotubes rooted from $\mathrm{Fe} / \mathrm{Al}$ 
nanoparticle array," Japanese Journal of Applied Physics, vol. 44, no. 1, pp. 457-460, 2005.

[59] C. He, N. Zhao, C. Shi, X. Du, and J. Li, "Synthesis of binary and triple carbon nanotubes over $\mathrm{Ni} / \mathrm{Cu} / \mathrm{Al}_{2} \mathrm{O}_{3}$ catalyst by chemical vapor deposition," Materials Letters, vol. 61, no. 27, pp. 4940-4943, 2007.

[60] W. Z. Li, J. G. Wen, M. Sennett, and Z. F. Ren, "Clean doublewalled carbon nanotubes synthesized by CVD," Chemical Physics Letters, vol. 368, no. 3-4, pp. 299-306, 2003.

[61] L. Ni, K. Kuroda, L.-P. Zhou, et al., "Kinetic study of carbon nanotube synthesis over $\mathrm{Mo} / \mathrm{Co} / \mathrm{MgO}$ catalysts," Carbon, vol. 44, no. 11, pp. 2265-2272, 2006.

[62] H. Yu, Q. Zhang, Q. Zhang, et al., "Effect of the reaction atmosphere on the diameter of single-walled carbon nanotubes produced by chemical vapor deposition," Carbon, vol. 44, no. 9, pp. 1706-1712, 2006.

[63] A. Tavasoli, K. Sadagiani, F. Khorashe, A. A. Seifkordi, A. A. Rohani, and A. Nakhaeipour, "Cobalt supported on carbon nanotubes-a promising novel Fischer-Tropsch synthesis catalyst," Fuel Processing Technology, vol. 89, no. 5, pp. 491-498, 2008.

[64] F. Benissad-Aissani, H. Aït-Amar, M.-C. Schouler, and P. Gadelle, "The role of phosphorus in the growth of vapourgrown carbon fibres obtained by catalytic decomposition of hydrocarbons," Carbon, vol. 42, no. 11, pp. 2163-2168, 2004.

[65] S. H. S. Zein and A. R. Mohamed, "Mn/Ni/ $/ \mathrm{TiO}_{2}$ catalyst for the production of hydrogen and carbon nanotubes from methane decomposition," Energy and Fuels, vol. 18, no. 5, pp. 1336-1345, 2004.

[66] M. C. Bahome, L. L. Jewell, K. Padayachy, et al., "Fe-Ru small particle bimetallic catalysts supported on carbon nanotubes for use in Fischer-Tröpsch synthesis," Applied Catalysis A, vol. 328, no. 2, pp. 243-251, 2007.

[67] L. Barthe, S. Desportes, M. Hemati, K. Philippot, and B. Chaudret, "Synthesis of supported catalysts by dry impregnation in fluidized bed," Chemical Engineering Research and Design, vol. 85, no. 6, pp. 767-777, 2007.

[68] H.-A. Ichi-oka, N.-O. Higashi, Y. Yamada, T. Miyake, and T. Suzuki, "Carbon nanotube and nanofiber syntheses by the decomposition of methane on group 8-10 metal-loaded MgO catalysts," Diamond \& Related Materials, vol. 16, no. 4-7, pp. 1121-1125, 2007.

[69] S. Takenaka, H. Umebayashi, E. Tanabe, H. Matsune, and M. Kishida, "Specific performance of silica-coated Ni catalysts for the partial oxidation of methane to synthesis gas," Journal of Catalysis, vol. 245, no. 2, pp. 392-400, 2007.

[70] M. C. Bahome, L. L. Jewell, D. Hildebrandt, D. Glasser, and N. J. Coville, "Fischer-Tropsch synthesis over iron catalysts supported on carbon nanotubes," Applied Catalysis A, vol. 287, no. 1, pp. 60-67, 2005.

[71] L. Piao, Y. Li, J. Chen, L. Chang, and J. Y. S. Lin, "Methane decomposition to carbon nanotubes and hydrogen on an alumina supported nickel aerogel catalyst," Catalysis Today, vol. 74, no. 1-2, pp. 145-155, 2002.

[72] J. M. Xu, X. B. Zhang, Y. Li, et al., "Preparation of $\mathrm{Mg}_{1-x} \mathrm{Fe}_{x} \mathrm{MoO}_{4}$ catalyst and its application to grow MWNTs with high efficiency," Diamond \& Related Materials, vol. 13, no. 10, pp. 1807-1811, 2004.

[73] Y. Chen and Y.-S. Lim, "A comparison of different preparation methods of Fe-Mo-Mg-O catalyst for the large-scale synthesis of carbon nanotubes," Materials Science Forum, vol. 510-511, pp. 66-69, 2006.

[74] S. P. Turano and J. Ready, "Chemical vapor deposition synthesis of self-aligned carbon nanotube arrays,"
Journal of Electronic Materials, vol. 35, no. 2, pp. 192-194, 2006.

[75] W. Qian, T. Liu, F. Wei, Z. Wang, and H. Yu, "Carbon nanotubes containing iron and molybdenum particles as a catalyst for methane decomposition," Carbon, vol. 41, no. 4 , pp. 846-848, 2003.

[76] Q. He, Q. Lin, L.-Z. Yao, W.-L. Cai, and Q. Zhu, "Effect of growth parameters on morphology of vertically aligned carbon nanotubes," Chinese Journal of Chemical Physics, vol. 20, no. 2, pp. 207-212, 2007.

[77] Z. Yu, D. Chen, B. Tøtdal, and A. Holmen, "Effect of catalyst preparation on the carbon nanotube growth rate," Catalysis Today, vol. 100, no. 3-4, pp. 261-267, 2005.

[78] Q. Zhang, W. Qian, Q. Wen, Y. Liu, D. Wang, and F. Wei, "The effect of phase separation in $\mathrm{Fe} / \mathrm{Mg} / \mathrm{Al} / \mathrm{O}$ catalysts on the synthesis of DWCNTs from methane," Carbon, vol. 45, no. 8, pp. 1645-1650, 2007.

[79] R. L. Vander Wal, T. M. Ticich, and V. E. Curtis, "Substratesupport interactions in metal-catalyzed carbon nanofiber growth," Carbon, vol. 39, no. 15, pp. 2277-2289, 2001.

[80] J.-F. Colomer, G. Bister, I. Willems, et al., "Synthesis of single-wall carbon nanotubes by catalytic decomposition of hydrocarbons," Chemical Communications, no. 14, pp. 13431344, 1999.

[81] S.-P. Chai, S. H. S. Zein, and A. R. Mohamed, "Synthesizing carbon nanotubes and carbon nanofibers over supportednickel oxide catalysts via catalytic decomposition of methane," Diamond \& Related Materials, vol. 16, no. 8, pp. 1656-1664, 2007.

[82] P. Piedigrosso, Z. Konya, J.-F. Colomer, A. Fonseca, G. Van Tendeloo, and J. B. Nagy, "Production of differently shaped multi-wall carbon nanotubes using various cobalt supported catalysts," Physical Chemistry Chemical Physics, vol. 2, no. 1, pp. 163-170, 2000.

[83] S.-P. Chai, S. H. S. Zein, and A. R. Mohamed, "Preparation of carbon nanotubes over cobalt-containing catalysts via catalytic decomposition of methane," Chemical Physics Letters, vol. 426, no. 4-6, pp. 345-350, 2006.

[84] K. C. Mondal, N. J. Coville, M. J. Witcomb, G. Tejral, and J. Havel, "Boron mediated synthesis of multiwalled carbon nanotubes by chemical vapor deposition," Chemical Physics Letters, vol. 437, no. 1-3, pp. 87-91, 2007.

[85] C. Vallés, M. Pérez-Mendoza, P. Castell, M. T. Martínez, W. K. Maser, and A. M. Benito, "Towards helical and Y-shaped carbon nanotubes: the role of sulfur in CVD processes," Nanotechnology, vol. 17, no. 17, pp. 4292-4299, 2006.

[86] H. Ago, N. Uehara, N. Yoshihara, et al., "Gas analysis of the CVD process for high yield growth of carbon nanotubes over metal-supported catalysts," Carbon, vol. 44, no. 14, pp. 29122918, 2006.

[87] S.-G. Kang, K.-K. Cho, K.-W. Kim, and G.-B. Cho, "Catalytic growth of single- and double-walled carbon nanotubes from Fe-Mo nanoparticles supported on MgO," Journal of Alloys and Compounds, vol. 449, no. 1-2, pp. 269-273, 2008.

[88] L. Ci, H. Zhu, B. Wei, J. Liang, C. Xu, and D. Wu, "Phosphorus-a new element for promoting growth of carbon filaments by the floating catalyst method," Carbon, vol. 37, no. 10, pp. 1652-1654, 1999.

[89] F. Benissad-Aissani, H. Aït-Amar, M.-C. Schouler, and P. Gadelle, "The role of phosphorus in the growth of vapourgrown carbon fibres obtained by catalytic decomposition of hydrocarbons," Carbon, vol. 42, no. 11, pp. 2163-2168, 2004.

[90] S. Zhan, Y. Tian, Y. Cui, et al., "Effect of process conditions on the synthesis of carbon nanotubes by catalytic decomposition 
of methane," China Particuology, vol. 5, no. 3, pp. 213-219, 2007.

[91] S. P. Chai, V. M. Sivakumar, S. H. S. Zein, and A. R. Mohamed, "The examination of $\mathrm{NiO}$ and $\mathrm{CoO}_{x}$ catalysts supported on $\mathrm{Al}_{2} \mathrm{O}_{3}$ and $\mathrm{SiO}_{2}$ for carbon nanotubes production via CCVD of methane," Carbon Science \& Technology, vol. 1, pp. 1-3, 2008.

[92] J.-H. Lin, C.-S. Chen, H.-L. Ma, C.-Y. Hsu, and H.-W. Chen, "Synthesis of MWCNTs on $\mathrm{CuSO}_{4} / \mathrm{Al}_{2} \mathrm{O}_{3}$ using chemical vapor deposition from methane," Carbon, vol. 45, no. 1, pp. 223-225, 2007.

[93] F. Ohashi, G. Y. Chen, V. Stolojan, and S. R. P. Silva, “The role of the gas species on the formation of carbon nanotubes during thermal chemical vapour deposition," Nanotechnology, vol. 19, no. 44, 2008.

[94] N. Q. Zhao, C. N. He, J. Ding, et al., "Bamboo-shaped carbon nanotubes produced by catalytic decomposition of methane over nickel nanoparticles supported on aluminum," Journal of Alloys and Compounds, vol. 428, no. 1-2, pp. 79-83, 2007.

[95] N. Zhao, C. He, Z. Jiang, J. Li, and Y. Li, "Physical activation and characterization of multi-walled carbon nanotubes catalytically synthesized from methane," Materials Letters, vol. 61, no. 3, pp. 681-685, 2007.

[96] L. K. Noda, N. S. Gonçalves, A. Valentini, L. F. D. Probst, and R. M. de Almeida, "Effect of Ni loading and reaction temperature on the formation of carbon nanotubes from methane catalytic decomposition over $\mathrm{Ni} / \mathrm{SiO}_{2}$, Journal of Materials Science, vol. 42, no. 3, pp. 914-922, 2007.

[97] I. Bustero, G. Ainara, O. Isabel, M. Roberto, R. Inés, and A. Amaya, "Control of the properties of carbon nanotubes synthesized by CVD for application in electrochemical biosensors," Microchimica Acta, vol. 152, no. 3-4, pp. 239-247, 2006. 

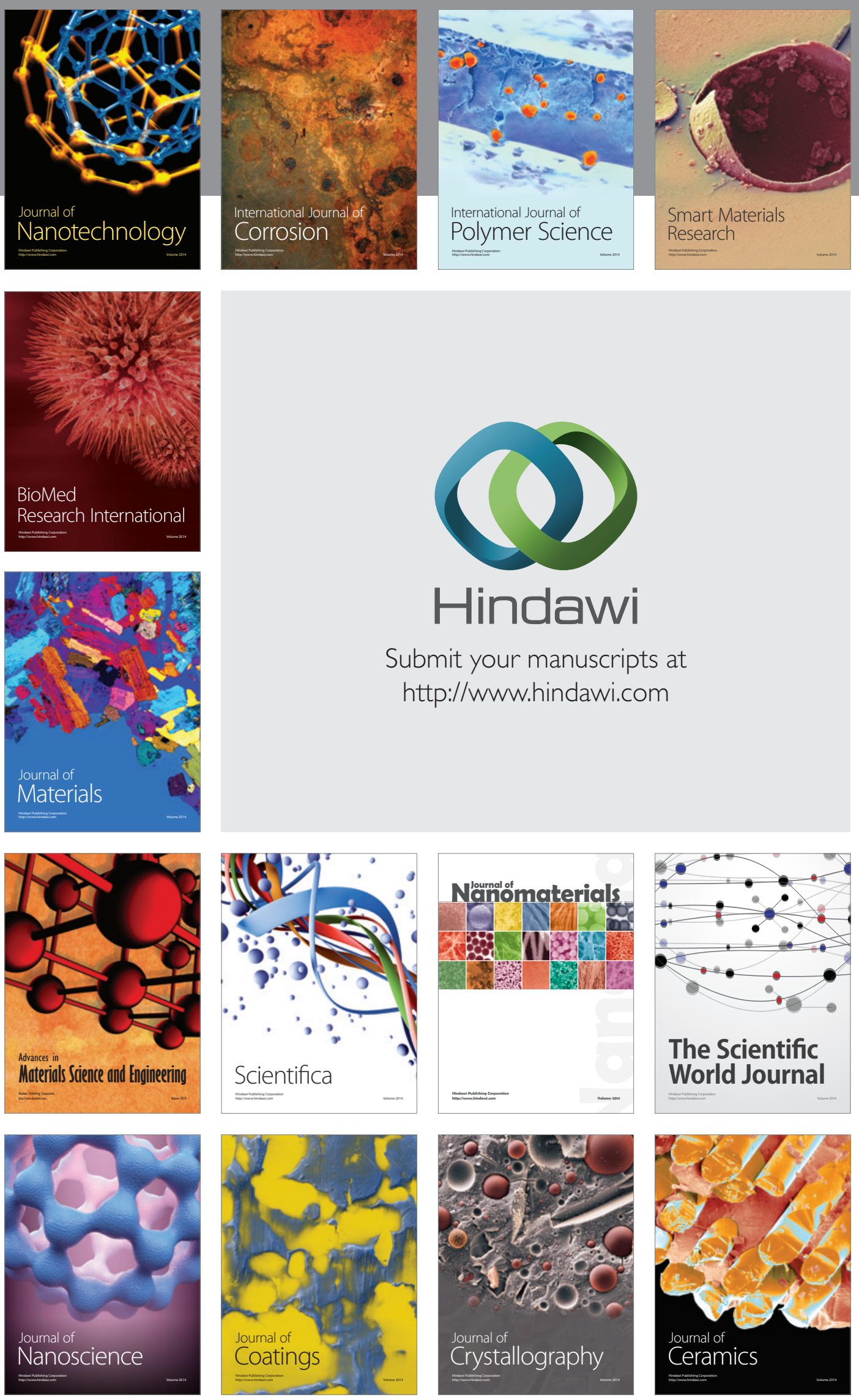

The Scientific World Journal

Submit your manuscripts at

http://www.hindawi.com

\section{World Journal}

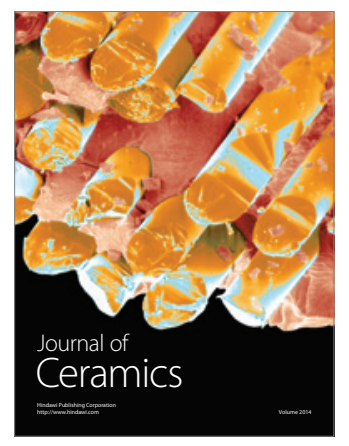

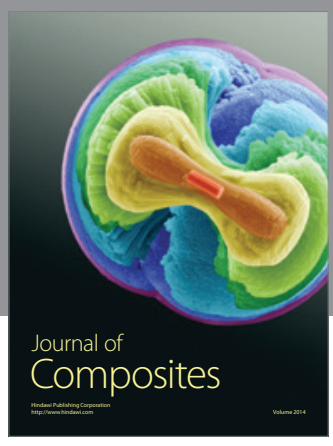
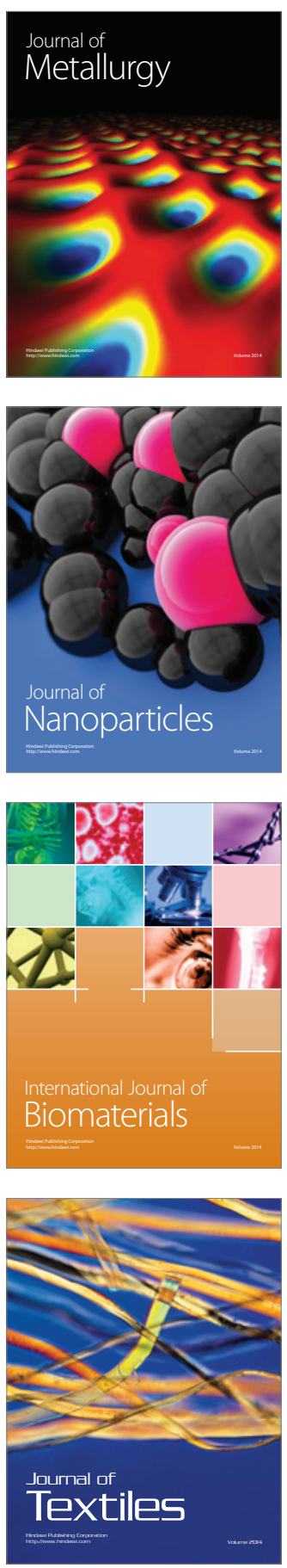